\title{
Comics with Drama: New Communication in Wedia
}

\author{
Jia-Wen $\mathrm{Hu}^{1, *}$ and Seng-Su Tsang ${ }^{2}$ \\ ${ }^{1}$ College of Management, National Taiwan University of Science and Technology, \\ Taipei, Taiwan \\ e-mail: marya810@yahoo.com.tw \\ ${ }^{2}$ Department of Business Administration, National Taiwan University of Science and Technology, \\ Taipei, Taiwan \\ e-mail: tsang@mail.ntust.edu.tw
}

Received March 5, 2015; revised May 25, 2015; revised July 23, 2015; accepted August 23, 2015; published October 31, 2015

\begin{abstract}
We-the-media (aka wedia) is a concept where the users of social networking sites, such as Facebook, turn into the broadcasters. This study used the popular application Bitstrips as the experiment tool. Facebook was used as the Wedia platform for publishing designed comics, then used the three elements of Goffman's dramaturgy model—role, scene and dialog-to analyze 265 comics created by 3 researchers and observe the audience's responses within 9 months. The results showed that people want to see a good story with positive dialogue, and prefer scene is school more than work. As all these elements are controllable, Wedia communication has the potential for more applications. We also found that including the elements of news, gambling and gift-giving tended to trigger greater response. Furthermore, We suggesting that such embedding of product information in web episodes (webisodes) with caricature could be a successful marketing strategy.
\end{abstract}

Keywords: Social network, Wedia, media, placement marketing, drama

This work was supported by the Natural Science Foundation of China (61102056, 61201132, 61402351), Fundamental Research Funds for the Central Universities of China (K5051301013) and the 111 Project of China (B08038). 


\section{Introduction}

Mobile phones have replaced television as the leading media in people's lives; Facebook and other social networking sites have replaced electronic mail and search engines as people's primary home on the Internet. People eager to display their lives publicly are an outcome of the contemporary phenomenon of rampant Wedia [1] (we-the-media).As hardware and platforms no longer pose barriers to unlimited communication, content is the key to getting attention.

In this study, we used Bitstrips, a free, downloadable application, to create 265 funny comics, and published them on 3 researchers' Facebook pages to observe audience responses. Facebook is an international platform, and these researchers' 8,008 friends come from all over the world, providing a robust (albeit not random) research sample. We used the Bitstrips mobile application to construct comics containing dramas, published them on Facebook, and observed audience responses.

\section{Literature Review}

\subsection{Wedia $=$ We-the-media}

Bourdieu's field theory suggests that the rise of the internet could generate a shift in the nature of journalism [2]. Every person is Wedia and every event is news [1]. This networked media environment presents a range of challenges for journalism, norms, and daily practices [3]. When everyone is a journalist, everyone is a publisher [4]. Just like observers turned into active participants [5].

Because of digital convergence, we live our lives as if we were in a transparent digital fish bowl, where we can present ourselves to a target audience through visuals. Your audience not only watches you, but also interacts with you and provides feedback through Likes, comments and shares. How can we control the elements to earn more responses, whether there are more attractive ways to present these contents, are all topics of our concern.

Past studies on Wedia have focused mainly on news published in the form of citizen reports. Readers-turned-reporters are publishing in real time to a worldwide audience via the Internet [1]. As technological barriers are lowered, the dominant role of the traditional mass media in gathering and reporting news is being overthrown; ubiquitous mobile technology allows us to receive news at any time and place. Digitization has occasioned new counter-hegemonic spaces and new forms of journalism, the radicalism of which is reflected in both its form and its content [6]. The definition and forms of journalism have thus been broadened. As hardware and platforms no longer pose barriers to unlimited communication, content is the key to getting attention.

\subsection{Dramaturgy}

The theory of dramaturgy given by [7] has been widely applied on the stages of mass media and politics. Politics is shaped by the mass media and the dramatic and engaging visual spectacles it presents; in this way, a dramaturgical social theory reflects society [8]. Both [7] and [8] described the concept of impression management as a means of meeting the audience's preferences.

The interactions between the service industry and consumers involve scripts; for example, call centers have their own manual to guide interactions with callers. The call center is a stage 
where actors-consultants play their roles [9]. Regardless of where [7]'s theory was applied, there is generally a clear distinction between the actors' performance on the front stage and back stage. The study shows that masks and impression management are still necessary on the Internet.

In recent years, scholars have proposed a "without walls" perspective. The back stage can be used to negotiate the stances that are later performed on the front stage, where wider and more ideological aspects of identity can be indexed [10]; thus, the wall between the front and the back stages are broken in Goffman's [7] dramaturgy. People can move through plots, which are actions especially apparent in the virtual world, on and off stage. This study extends and applies this concept.

The avatar was designed based on the researcher's identity. Next, Facebook friends who also used this application software and agreed to actively participate in the situation as actors were invited to become part of the comic and jointly play out a situation. This type of scenario can enable us to gauge the audience's level of interest and genuine responses without walls.

Table 1. Comparison of a real and a virtual theatre

\begin{tabular}{lll}
\hline Item & Real Theatre & Virtual Theatre \\
\hline Role & $\begin{array}{l}\text { Follows a script with fixed arrangements } \\
\text { for personality and presentation. }\end{array}$ & $\begin{array}{l}\text { Does as one pleases, deciding ones image } \\
\text { and free to change it at will. }\end{array}$ \\
\hline Scene & Fixed scene that takes time to change & $\begin{array}{l}\text { Any time and place, diverse presentation of } \\
\text { content. }\end{array}$ \\
\hline Dialog & Fixed script played out line by line & Free expression, improvisation. \\
\hline
\end{tabular}

After comparing a theater and virtual theater in Table 1, it is easy to see the secret to the drama that is presented in online comics-avatars can be created at will, the design can be changed at any time, any scene can be selected, and the dialog depend on the mood. After observing the responses from friends, new images can be designed, which is the main focus of our experiment.

\section{Method}

The method applied in this study encompassed implementation of an experiment involving participant observation, followed by analysis of the results.

\subsection{Experiment Design}

The procedures are shown in Fig. 1. Everyone can design comics by themselves. First, a hairstyle, facial features, and clothing are selected to design a caricature. Next, a Facebook friend is invited to play a role and the avatars are put into a comic situation.

To prevent the popularity of comic characters from interfering with the experiment results, researchers fixed the main characters Role1 and Role2 and used them as a control variable (Fig. 2). Role 1 is the researcher, role 2 is his (or her) designated friend. 

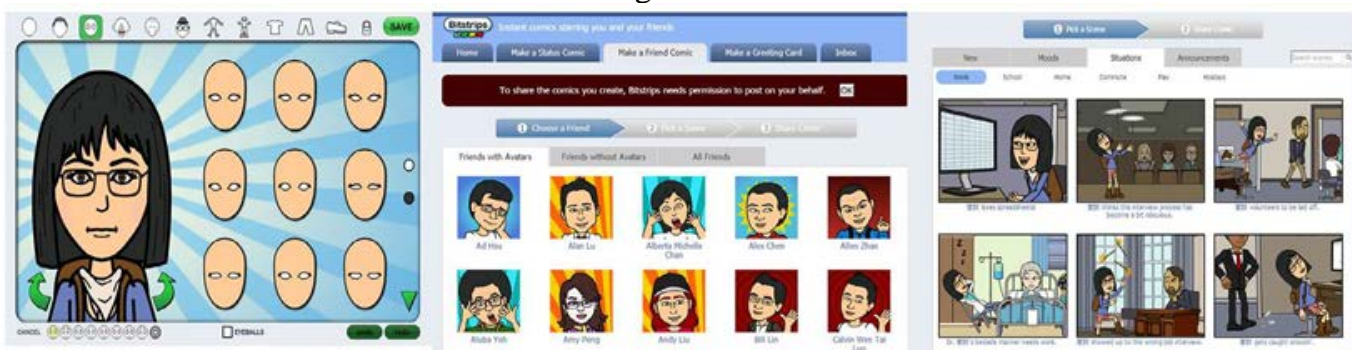

Fig. 1. Create comics step by step with APP

After each comic was completed, it was posted on the Facebook page of 3 researchers, and the responses of their friends, such as the Likes, comments, and shares, were recorded. This process was completed and recorded in 9 months.

The three researchers shared the following characteristics: 1 . They all frequently used this APP and created comics of similar quality; 2.They have a similar number of FB friends at around 2,700 . These two characteristics are very good control variables that allow comics to be compared on the same basis.

However, the three researchers come from entirely different backgrounds: Researcher A, Professor $\mathrm{Hu}$, is a 42 year old program director with 2,778 Facebook friends, who are in the ages 15 75 and from all walks of life around the world. The sample is an epitome of all Facebook users. 32\% (892 users) of them were media workers and their participation in the experiment did indeed help the exposure of comics

Researcher B is a 22 year old female college student, who is the Student Body President, with 2,597 Facebook friends in the ages 17 27, including students and graduates. Researcher $\mathrm{C}$ is a 35 year old male computer engineer who was just married; his Facebook friends are mid to high level white collar workers in the ages 28 65. The three researchers do not have many common friends (AB32+AC217+BC4=253), who may prefer different themes, making them suitable for comparing the response of different groups.

During this period the three researchers posted 265 comics (Researcher-A-111 comics; Researcher-B-64 comics; Researcher-C-90 comics), coming in contact with a total of 8,008 Facebook users from all three groups. (Total number of Facebook friends 8,261 - 253 common friends $=8,008)$.

\subsection{Participant Observation}

Participant observation is when the researcher plays the parts of both observer and participant [5]. Under this circumstance, the observer is not considered an outsider and can maintain a natural environment wherein to observe, thereby reducing interference by spectators and allowing the observer to obtain data that is closer to the truth. According to [5], it is important to become friends, or at least be accepted in a community to obtain quality data.

\subsection{Content Analysis}

Qualitative: The comics were coded by date and the contents were analyzed using the three dramaturgical elements of role, scene, and dialog (Fig. 2). 


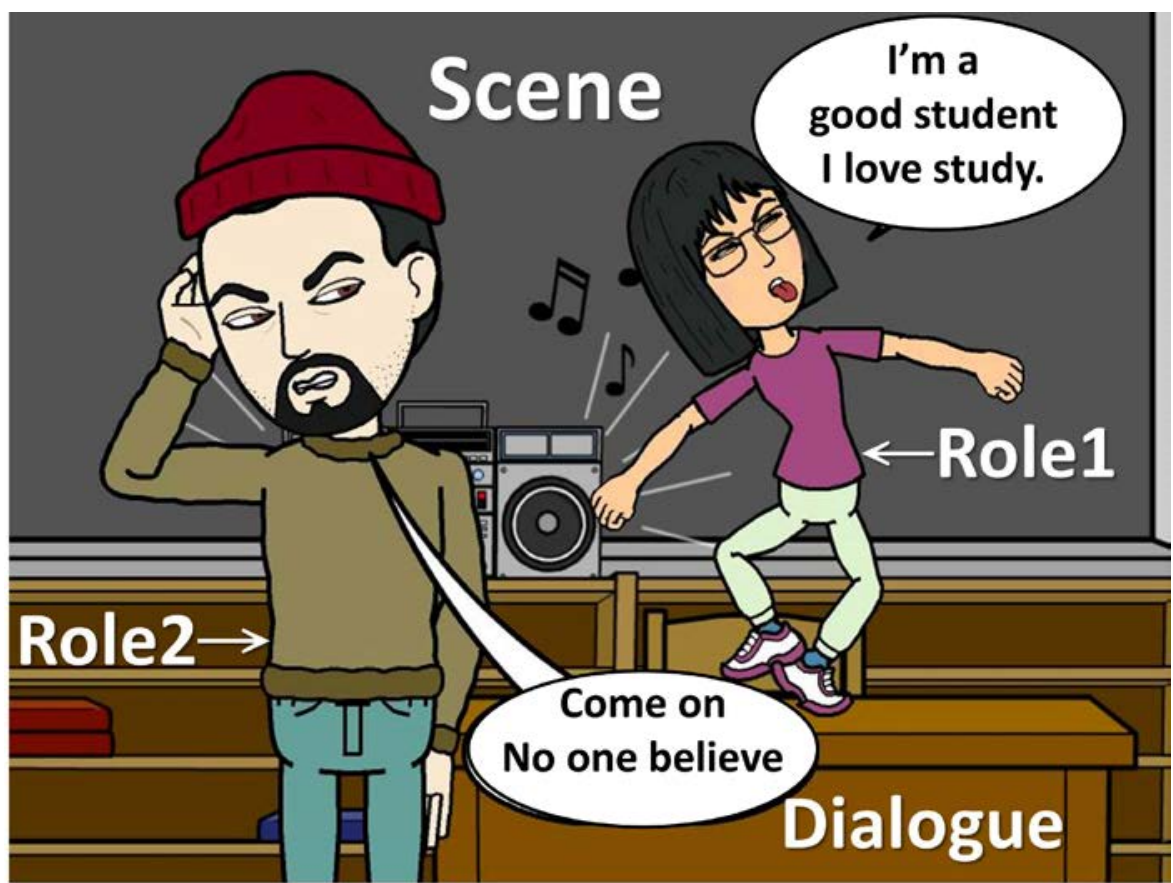

Fig. 2. Roles, scene, and dialog (designed by researcher A)

For the first independent variable-role — we investigated the audience response to a number of roles. For the second independent variable — scene-we wished to understand if the audience had any preferences among the five scenarios of school, workplace, playful environment, color background, and home. Dialog was considered essential in this process, and so was defined as the moderator (Fig. 3).
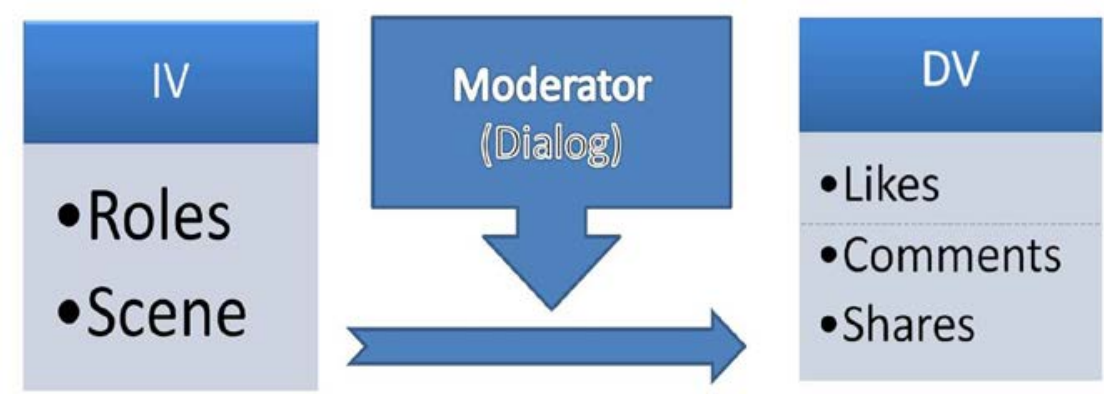

Fig. 3. Variables and moderator

Quantitative: Using the above mentioned categories, we used the Likes, comments, and shares for each comic as the dependent variables. A $t$-test was applied to factor pairs, e.g., the number of roles was divided into single player and two players, scenes were divided into public and private, and dialog was divided into positive, ironic, and ordinary. 


\section{Results}

\subsection{Role Effect}

Role refers to the actors participating in the performance, i.e., the number of actors appearing in the comic. Table 2 shows that the number of roles did not affect the number of Likes; there was no significant difference in the number of Likes for comics with a single role and those with two roles, with the mean for the Likes for all comics at 63.7.

When making the comics we found that with comics that only had one role, as shown in Fig. 6, we could only choose from different colors to use as the background and only present a monologue. It was impossible to let the story play out through a dialogue. This was a constraint using the APP for the experiment. Hence, there is indeed a severe imbalance in the number of comics with one role and two roles to maintain the diversity of scenes and dialogue. It is for this reason we used the t-test to examine the influence of number of roles on the number of likes and comments.

The $t$-test results had a $p$-value of 0.395 . Thus, it was insignificant at the 0.05 level. Therefore, the number of roles did not have a significant effect on the number of comments. The $t$-test results had a $p$-value of 0.401 . Thus it was insignificant at the 0.05 level. Similar to a real theater, the number of actors does not directly affect the box office. The main factors are whether the actors' performances meet the audience's expectations and whether the drama arouses sympathetic responses.

Table 2. Number of roles and audience response (Researcher A)

\begin{tabular}{lrrrrr}
\hline Role players & Comics & Likes & Means of Likes & Comments & $\begin{array}{r}\text { Means of } \\
\text { Comments }\end{array}$ \\
\hline Only 1 actor & 23 & 1,434 & 62.3 & 66 & 2.9 \\
2 actors and above (inclusive) & 88 & 5,632 & 64.0 & 240 & 2.7 \\
$\quad$ SUM & 111 & 7,066 & 63.7 & 306 & 2.8 \\
\hline
\end{tabular}

We learned that the number of actors, whether it may be only one, two or more (Figs. 12 and 13), has no effect on the response of the audience. Hence, number of actors is not the key to whether or not a comic is popular.

\subsection{Scene Effect}

Scene is where the story is staged and the characters interact. This study also aimed to understand whether people liked to look at the actors' private lives back stage [7]; thus, we separated the scenes into real and virtual scenes, in which real scenes are divided into public and private scenes. Virtual scenes refer to single color backgrounds like Cyclorama, or playful scenes like outer space or heaven.

The different scenes of comics are listed in Table 3. First, public scenes are mainly on the topics of work and school life. Private scenes include the everyday affairs of a couple at home, and contents are related to feelings. Virtual scenes express fantasies and monologues related to self-expectations. After defining each type of scene, we conduct further analysis below.

Of the 111 comics posted by Researcher A, 37 take place in more private scenes, such as kitchen, bedroom or living room, with the aim of bringing the actor's private life to the front stage to observe the audience's response. Based on the number of Likes and comments for each of the 3 scenes, the audience did not have any special preferences for scenes set in home. 
Table 3. Correlation between scenes, topics and audience response (researcher A)

\begin{tabular}{|c|c|c|c|c|c|c|c|}
\hline Scene & $\begin{array}{c}\text { Comic } \\
\text { Conte } \\
\text { nt }\end{array}$ & $\begin{array}{c}\text { Background } \\
\text { Topic }\end{array}$ & Comics & Likes & $\begin{array}{l}\text { Means of } \\
\text { Likes }\end{array}$ & Comments & $\begin{array}{c}\text { Means of } \\
\text { Comment } \\
\text { s } \\
\end{array}$ \\
\hline \multirow{2}{*}{ Public } & \multirow{2}{*}{$\begin{array}{l}\text { Life } \\
37\end{array}$} & Work & 19 & 872 & 45.9 & 30 & 1.6 \\
\hline & & School & 18 & 1,595 & 88.6 & 78 & 4.3 \\
\hline \multirow{3}{*}{$\begin{array}{l}\text { Private } \\
\text { (Home) }\end{array}$} & \multirow{3}{*}{$\begin{array}{c}\text { Feeling } \\
37\end{array}$} & Kitchen & 12 & 678 & 56.5 & 32 & 2.7 \\
\hline & & Bedroom & 7 & 396 & 56.6 & 21 & 3.0 \\
\hline & & Living room & 18 & 1180 & 65.6 & 52 & 2.9 \\
\hline \multirow{3}{*}{ Virtual } & \multirow{2}{*}{$\begin{array}{l}\text { Fancy } \\
37\end{array}$} & Playful & 20 & 1,251 & 62.6 & 35 & 1.8 \\
\hline & & Cyclorama & 17 & 1,094 & 64.4 & 58 & 3.4 \\
\hline & Sum & 7 & 111 & 7,066 & 63.7 & 306 & 2.8 \\
\hline
\end{tabular}

However, after comparing the number of likes for comics set in the 37 public scenes and those set in 37 private scenes, there was no significant difference, with a $p$-value of 0.158 . There also was no significant difference in the number of comments with a $p$-value of 0.484 . Although we attempted to put back stage scenes in the front stage, the audience did not show any preference for these private scenes.

Table 4. Scenes t-test (Researcher A's 111 comics)

\begin{tabular}{cccc}
\hline Scene & Comic Content & Likes $(\boldsymbol{p}$ - value) & Comments(p-value) \\
\hline Public vs. Private & Life vs. Feeling & 0.1580 & 0.4841 \\
Private vs. Virtual & Feeling vs. Fancy & 0.3100 & 0.3129 \\
Virtual vs. Public & Fancy vs. Life & 0.2657 & 0.2976 \\
\hline
\end{tabular}

We further compiled Table 4 and found that the $p$-value for number of likes did not reach level of significance after conducting $t$-test for each pair of scenes (Public, Private and Virtual). The same situation occurred for comments. Hence, we found that the audience's response was not correlated to public, private or virtual scenes; private scenes were not necessarily more popular than public scenes. We conducted further analysis because we were curious if these seven types of scenes had any special meaning to the audience.

We made an interesting discovery when further analyzing which of the 7 scenes the audiences like the most and the least. As shown in Table 3, the scenes in a school were significantly more popular than the others, receiving an average of 88.6 Likes, which is higher than the average of 63.7 likes. School-life memories also received more comments at an average of 4.3 comments, which is significantly higher than the average of 2.8 comments. In the theater, common memories have always been effective in arousing sympathetic responses. Such scenes awaken memories of the childhood classroom, which could result in conversations between old classmates. Campus life (Fig. 2) is also a common experience for many people, which became the most favored scene.

Table 3 shows that the audiences disliked work scenes the most (a mean of 45.9 Likes) such as scenes in an office (Fig. 4). When we applied a $t$-test to the number of Likes received by the 18 comics that take place in a school and the 19 comics that take place at work, the $p$-value was almost zero; moreover, the $p$-value for the number of comments was 0.008 , both showing significance. It was observed that most of the audience preferred the school scenes (Fig.2), Work scenes (Fig. 4) were found to be the least popular. 


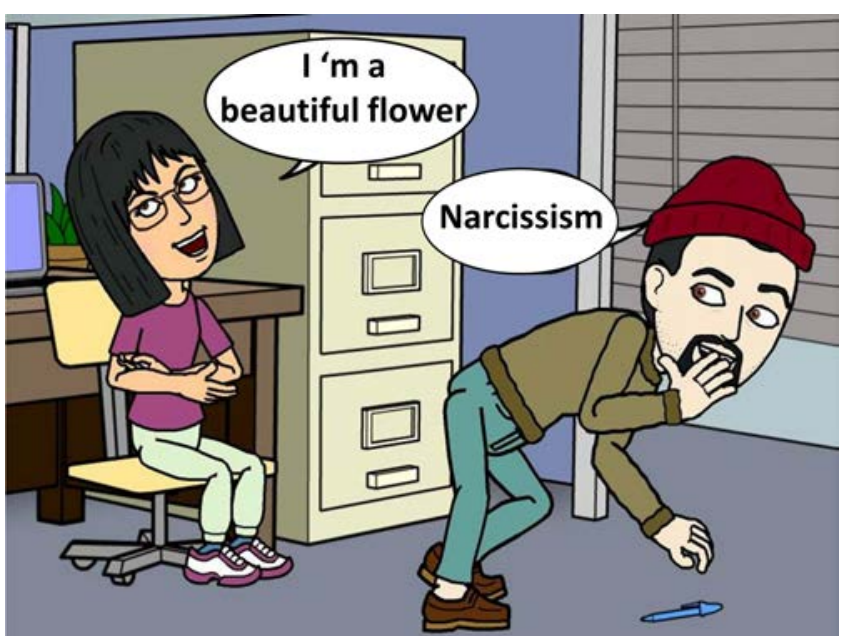

Fig. 4. People don't like work scene (Designed by researcher A)

Because people generally log on to Facebook for leisure purposes, they have no desire to discuss work. This is especially true when a person is already at work and being unproductive using their mobile phone or tablet PC to log on to Facebook; therefore, they do not want to be reminded that they are currently at work.

To verify if there would be a similar situation in different groups, Researcher B made 64 comics on topics of life, all of which had 2 actors with a positive dialogue, controlling the number of actors and dialogue to compare the effect of two topics in public scenes on audiences' preferences, as shown in Table 5.

Table 5. Correlation between scenes (work vs. school) and audience response (Researcher B)

\begin{tabular}{ccccccc}
\hline $\begin{array}{c}\text { Comics } \\
\text { Scene }\end{array}$ & $\begin{array}{c}\text { Background } \\
\text { Topic }\end{array}$ & Comics & Likes & Means of Likes & Comments & $\begin{array}{c}\text { Means of } \\
\text { Comments }\end{array}$ \\
\hline Public & Work & 32 & 1,276 & 39.9 & 53 & 1.7 \\
\cline { 2 - 7 } & School & 32 & 2,612 & 81.6 & 168 & 5.3 \\
\hline & Sum & 64 & 3,888 & 60.8 & 221 & 3.5 \\
\hline
\end{tabular}

Researcher B is a female college senior who has a part-time job and is about to graduate. She knows many people because she is the Student Body President and has 2,597 Facebook friends, who are in the ages 17 27 years old. Her Facebook friends are relatively young and prefer topics related to campus life, as shown in Table 5 . The 32 comics related to school received an average of 81.6 likes and 5.3 comments, far higher than any other type of comic. In the comments they discussed which courses were easier to pass, and what events they wanted to go to; they were especially enthusiastic about restaurant discounts, such as Pizza buy one get one free (Fig. 5), discussing the flavor and menu(18 comments).

In contrast, the 32 comics related to work only received an average of 39.9 likes, far lower than the average of 60.8 for the 64 comics; of the average 1.7 comments (Table 5), most were encouragements, such as "you can do it." Some students clearly pointed out that they were about to graduate and there was more than enough time in the future to talk about work, so they should not talk about it now, avoiding the topic. We further conducted $t$-tests and found that the $p$-values were all close to zero. This shows that audiences have clear preferences when it comes to school and work related scenes in both number of likes and comments. 


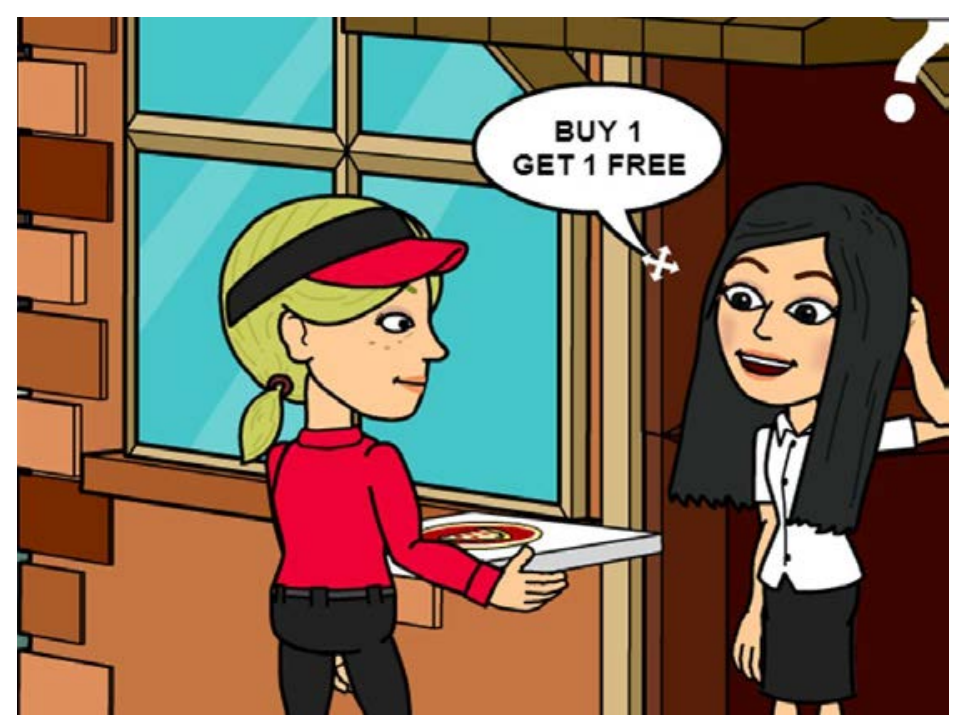

Fig. 5. People like food and discount (Designed by researcher B)

Media workers accounted for the highest percentage of Researcher A's Facebook friends, while the majority of Researcher B's Facebook friends are students. The two groups of friends have very different ages and lifestyles and provide a good opportunity for comparison. Both groups, however, did not like to see comics about work on Facebook, and were more interested in comics about campus life. The student group was not only more likely to click on "like", but also more willing to leave a comment, most of which made no sense at all, but they still enjoyed it.

\subsection{Dialogic Effect}

Dialog refers to the monologue of a single actor (Fig. 6) or the dialog between two actors in the comic, presented in the form of text in a dialog box. Dialog not only represents the interaction between the characters, but also allows the plot to develop, which is where an individual style is displayed or messages are communicated. However, this aspect has rarely been discussed in dramaturgical applications [7].

Of the 111 comics made by Researcher A in this experiment, 37 had a positive dialog, 37 had an ordinary dialog, and 37 used irony in the dialog (Fig. 6). The results of the observations are in Table 6.

Table 6. Effect of dialog on audience response (Researcher A)

\begin{tabular}{lrrrrrr}
\hline Dialog & Comics & Likes & $\begin{array}{r}\text { Means of } \\
\text { Likes }\end{array}$ & Comments & $\begin{array}{r}\text { Means of } \\
\text { Comments }\end{array}$ & Shares \\
\hline Positive & 37 & 2,964 & 80.0 & 138 & 3.7 & 10 \\
Ordinary & 37 & 1,805 & 48.8 & 53 & 1.4 & 3 \\
Ironic & 37 & 2,297 & 62.1 & 115 & 3.1 & 6 \\
\hline Sum & 111 & 7,066 & 63.7 & 306 & 2.8 & 19 \\
\hline
\end{tabular}

The audience liked positive dialogs as Fig. 6 (an average of 80 Likes) and responded with encouragement such as commenting "GOGOGO." The audience also seemed pleased about being able to understand the ironic dialog, which made them believe in their own intellect and assert their superiority over the character being mocked. Ordinary dialog was more easily overlooked by audiences. They were not inspired by this and did not even care to comment. 


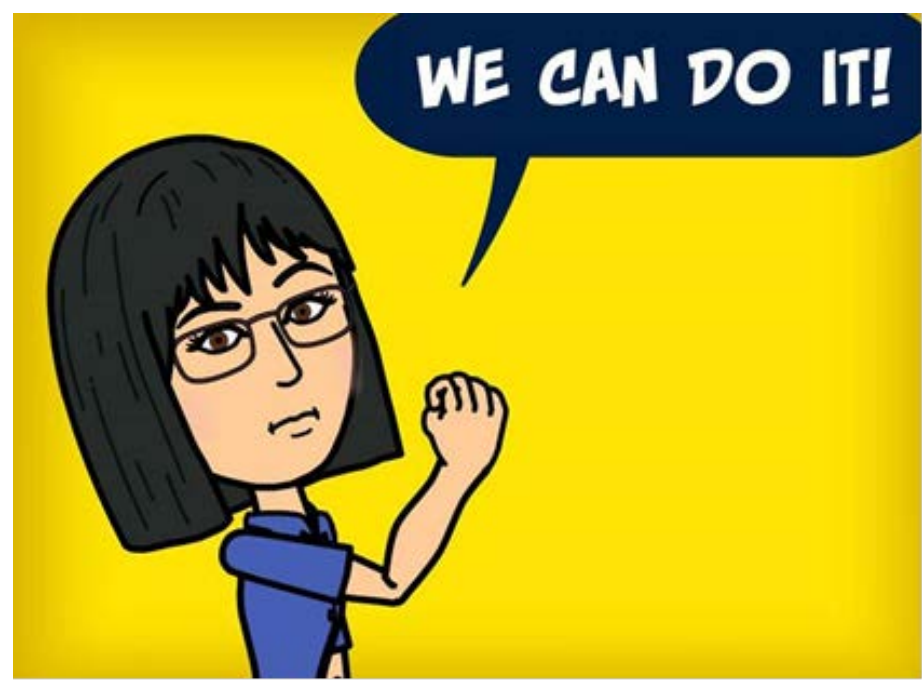

Fig. 6. Positive monologue (Designed by researcher A)

We performed a $t$-test on pairs of the three categories, as shown in Table 7. The results were as follows: the p-value was 0.0011 for the number of Likes given to positive dialog (Fig. 6) and ironic dialog, indicating a significant difference. Positive dialog and ordinary dialog had a significantly different effect on audience preference ( $p$-value nearly 0 ), and the number of comments on the positive dialog comics also reached a level of significance $(p=0.0015<$ 0.05 ) compared to the ordinary dialog comics. There was also a significant difference ( $p=$ $0.0007<0.01)$ in the number of Likes for ordinary dialog comics and ironic dialog comics (Fig. 4).

There was a significant difference between any two of these three dialog types. This indicates that dialog has a decisive effect on audience response, and is an important moderator along with role and scene.

Table 7. Dialog t-test (researcher A)

\begin{tabular}{lcc}
\hline \multicolumn{1}{c}{ Dialog t-test } & $\boldsymbol{p}$-value (Likes) & $\boldsymbol{p}$-value (comments) \\
\hline Positive vs. Ironic & 0.0011 & 0.4025 \\
Positive vs. Ordinary & 0.0000 & 0.0015 \\
Ordinary vs. Ironic & 0.0007 & 0.0052 \\
\hline
\end{tabular}

Most people liked positive dialog, such as "Yes! We can!” (Fig. 6). Interesting dialog, such as a practical joke between the characters (Fig. 4), also attracted attention from the audience. Ordinary dialog, such as describing your day or showing emotion (no dialog, only facial expression), did not capture the interest of the audience, possibly because these comics were not effective or the audience could not understand what the character wanted to express.

To verify if a similar situation occurs in different groups, Researcher $C$ made 90 comics to express feelings. All of the comics had 2 actors in a private scene, controlling the number of actors and scene to compare the effect of three types of dialogue on the audience's response, as shown in Table 8. 
Table 8. Effects of dialog on audience response (Researcher C)

\begin{tabular}{llrrrrrr}
\hline Scene & Dialog & Comics & Likes & $\begin{array}{l}\text { Means of } \\
\text { likes }\end{array}$ & Comments & $\begin{array}{r}\text { Means of } \\
\text { Comments }\end{array}$ & Shares \\
\hline Private & Positive & 30 & 1,672 & 55.7 & 176 & 5.7 & 5 \\
(Home) & Ordinary & 30 & 904 & 30.1 & 86 & 2.9 & 0 \\
& Ironic & 30 & 1,391 & 46.4 & 113 & 3.8 & 3 \\
\hline & Sum & 90 & 3,967 & 44.1 & 375 & 4.2 & 8 \\
\hline
\end{tabular}

Researcher $C$ is a 35 year old male computer engineer who works at a bank and was just married. He has 2,597 Facebook friends who are mid- to high-level white collar workers in the ages 28 65 years old. Similar to the Researcher A, his Facebook friends prefer positive dialogue (mean of 55.7 likes); they did not have much interest in ordinary dialogue at home (mean of 30.1 likes). It is noteworthy that this group of people was not as enthusiastic in giving likes compared with Researcher A and Researcher B, but they were the most willing to leave comments, especially dialogue related to health.

Fig. 7 shows a comic that promotes a clinic in an alley and uses a humorous play of words; the comic received 43 likes and 9 comments from worried family and friends. Fig. 8 has a positive dialogue that calls on people to donate blood and received 61 likes and 7 comments of people agreeing to go donate blood together. When comics about travel and food were posted, members of group $\mathrm{C}$ would still steer the discussion towards health care, which is a characteristic of the group of white collar workers.

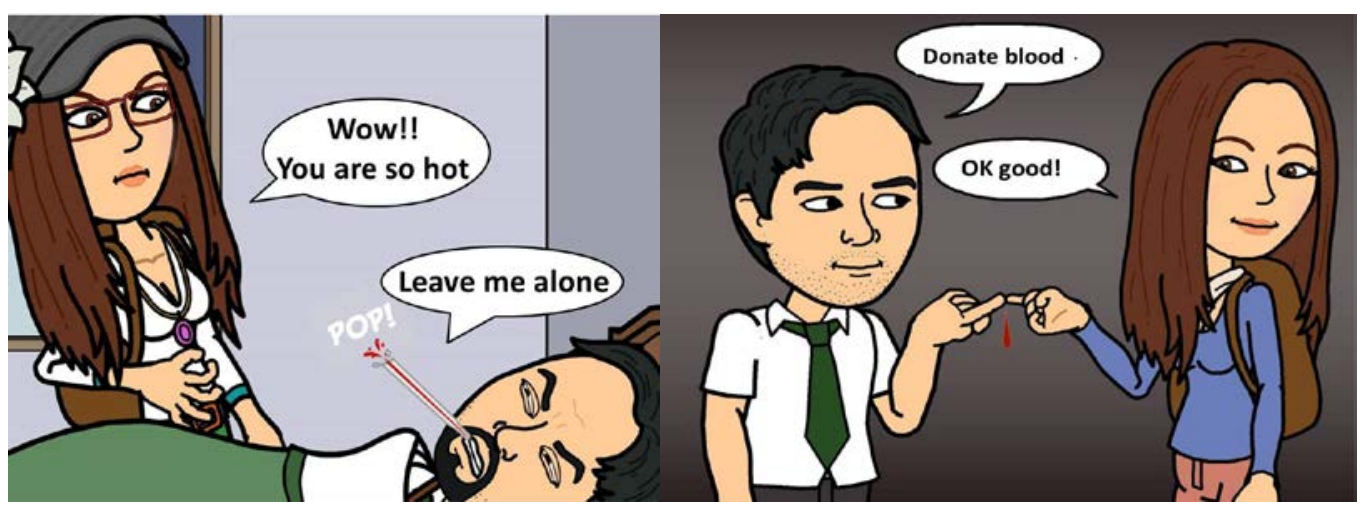

Fig. 7. Private ironic (Researcher C)

Fig. 8. Blood donation campaign promote

They also offered many opinions on baby products; some Facebook friends tried to stop fighting between couples with ironic dialogue, or shared the comics to bring others into the conversation; this is clear from results of the $t$-test shown in Table 9 that they were willing to comment on both Positive (Fig. 8) vs. Ironic (Fig. 7) comics ( $p$-value of 0.0989 indicates no significant difference), but there were significant differences between each pair in the number of likes. This is the same as Researcher A's hypothesis that people like to see positive dialogue, followed by ironic dialogue, but will not click like when they see ordinary dialogue.

Table 9. Dialog t-test (Researcher C)

\begin{tabular}{lcc}
\hline \multicolumn{1}{c}{ Dialog t-test } & $\boldsymbol{p}$-value (Likes) & $\boldsymbol{p}$-value (comments) \\
\hline Positive vs. Ironic & 0.0410 & 0.0989 \\
Positive vs. Ordinary & 0.0000 & 0.0388 \\
Ordinary vs. Ironic & 0.0000 & 0.3140 \\
\hline
\end{tabular}


This study also found that when the actors' dialog with gambling things, it will awaken the gambler in everyone and receive many likes. Whether the bet proposed in the researcher A's comic is on who graduates first or on whether someone can clean a room within a time limit; the bet made in Researcher B's comic was who would find a job first; and the bet made in Researcher C's comic was to guess the gender of the baby and when the baby will be born. Whenever there was a bet, many people will stop by virtually to make a bet or leave a comment. This element successfully attracted a large audience each time.

\subsection{Placement Marketing}

The three researchers further conducted an experiment with product placements on different situational comics (see Table 10). Of the 265 comics (A111+B64+C90), a total of 42 comics $(\mathrm{A} 14+\mathrm{B} 10+\mathrm{C} 18)$ used product embedding, but the average number of likes the comics received was not lower than the average of each group. This shows that comics for a specific purpose do not have a negative effect on the audience. In fact, the comics had above average number of comments, and attention creates business opportunities.

Table 10 lists embedded contents that the three groups responded the most to, in which common items include food, life, and news. These topics did not raise their guard. Differences between these topics are analyzed using actual examples below.

Of the 111 comics posted by Researcher A, 14 were used for placement marketing. The 14 comics received an average of 70.0 likes, higher than the overall average of 63.7 likes. Since Researcher A is a director, his recommendations of TV programs, movies and public relations events were believed to be credible, and his Facebook friends engaged in enthusiastic discussions without any suspicions.

For example, the comic recommending the TV series "House of Paper" received 51 likes and 5 comments, and the Facebook friends even began discussing the story and did not suspect it to be an advertisement. Comics with entertainment related topics received an average of 3.1 comments, higher than the overall average of 2.8 comments. We give a few more examples below for the reader to better understand how comics are combined with promotions.

Table 10. Effect of product embedding

\begin{tabular}{|c|c|c|c|c|c|c|}
\hline Item & \multicolumn{2}{|c|}{ Researcher-A } & \multicolumn{2}{|c|}{ Researcher-B } & \multicolumn{2}{|c|}{ Researcher-C } \\
\hline Career & \multicolumn{2}{|c|}{ TV Director } & \multicolumn{2}{|c|}{ Graduate Student } & \multicolumn{2}{|c|}{ Computer Engineer } \\
\hline FB friends & \multicolumn{2}{|c|}{2,778} & \multicolumn{2}{|c|}{2,597} & \multicolumn{2}{|c|}{2,886} \\
\hline \multirow[t]{2}{*}{ Comics } & Embed & ALL & Embed & ALL & Embed & ALL \\
\hline & 14.0 & 111.0 & 10.0 & 64.0 & 18.0 & 90.0 \\
\hline Means of Likes & 70.0 & 63.7 & 61.2 & 60.8 & 45.0 & 44.1 \\
\hline Means of Comments & 3.1 & 2.8 & 6.0 & 3.5 & 6.0 & 4.2 \\
\hline Means of Shares & 0.4 & 1.1 & 1.0 & 1.3 & 1.0 & 0.1 \\
\hline Scenes & \multicolumn{2}{|c|}{ Public, Private, Virtual } & \multicolumn{2}{|c|}{ Public only } & \multicolumn{2}{|c|}{ Private only } \\
\hline Interest topic & \multicolumn{2}{|c|}{$\begin{array}{c}\text { Food, Life, news, } \\
\text { TV, Shopping, Activity }\end{array}$} & \multicolumn{2}{|c|}{$\begin{array}{l}\text { Food, life, news } \\
\text { Campus activity }\end{array}$} & \multicolumn{2}{|c|}{$\begin{array}{c}\text { Food, Life, news } \\
\text { Healthy, Baby, Goods }\end{array}$} \\
\hline
\end{tabular}

As the results show that placement marketing was the most successful when checking into a restaurant on Facebook (Fig. 9). The comic uses a wedding anniversary as a cover, but in fact the real purpose is to recommend a steakhouse. The comic received 93 likes and 3 comments, one Facebook friend indicated he went to the restaurant before, and the other two discussed the address and transportation information of the restaurant.

Thus, placement marketing in comics that contain these elements such as positive dialog 
and romantic situation can be effective. An interesting story will make an audience less defensive and open people's minds to accept the information that one wishes to communicate.

This study indicates that, wedia (we-the-media) members' most favorite items. Thus, embedding product information in webisodes (web episodes) that contain these elements such as news and gifts can be effective.

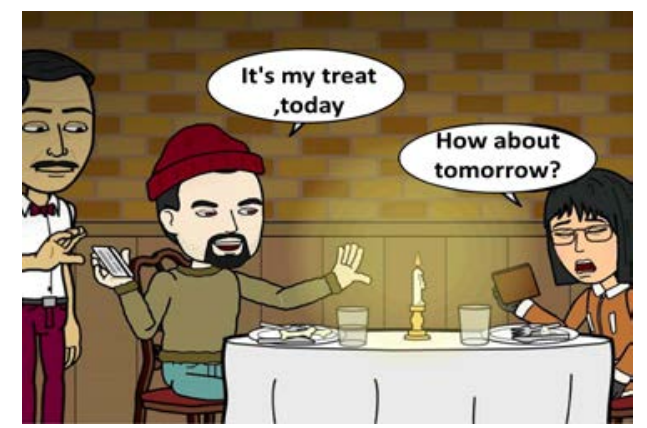

Fig. 9. A romantic dinner in a good restaurant for anniversary (Researcher A)

We also found that everyone loves surprises and gifts, especially around an anniversary (see Fig. 9) or holidays. Using Fig. 10 as an example, it seems that the boy is giving the girl a surprise New Year present, but in fact the description provides information of the launch of a new iPad. Instead of talking about a product directly, telling a story is often easier, especially within the context of a comic situation. It lowered the audience's guard and allowed the information to be treated as news and shared (Fig. 10-Receieved 88 likes and 3 shares).

Furthermore, audiences were originally concerned about popular topics, and such topics are easy to use for placement marketing. Comic uses the issue of food safety to promote soymilk because milk has toxins that cause cancer. The comic received 74 likes and comments in support. It was also shared as health knowledge. This group of consumers supported the new concept without suspecting that it might be a soymilk advertisement.

The concern for health is more apparent among older groups, i.e. Facebook friends of Researcher A and C (Figs. 7, 8), and not as clear in the student group. All three groups regardless of age were concerned about weather reports, e.g. an earthquake occurred or a typhoon is coming.

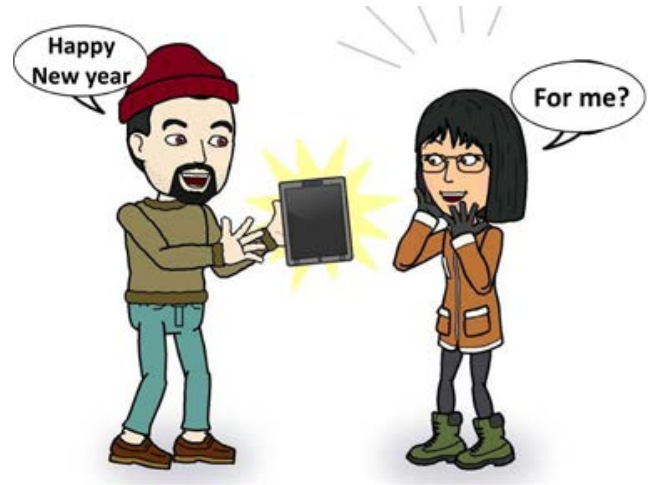

Fig.10. A product embedding as the gift in the new year (Designed by researcher A)

Even though comics with couples showing their love will get complaints that it is too much, friends will not hesitate to like the comic. This shows people's envy and desire for happiness and love. Hence, any product can be successfully embedded into the comic as a gift of 
affection, and an advertisement can reasonably appear in such a scenario. For example, which shows two people eating one "newly launched" ice cream cone in Family Mart, operates the same way and received 66 likes. The number of likes increases when a gift was involved, this above-average interest was observed regardless of the content of the gift, whether it may be a romantic dinner, an iPad or an ice cream.

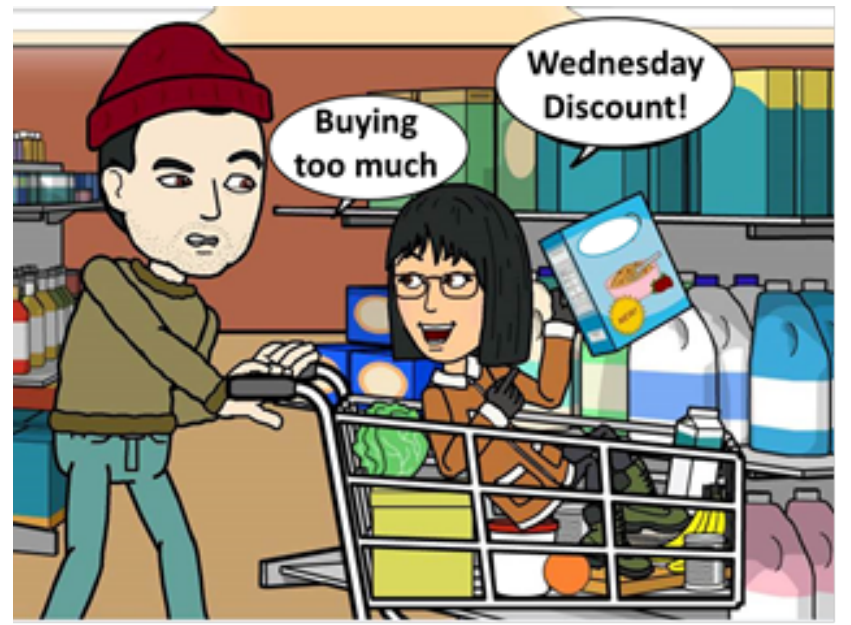

Fig. 11. Discount massage shared as good news (Researcher A)

People on the internet like to share good news, giving each other information on discounts every now and then. Such as Fig. 11 (50likes; 3comments; 3shares), the point collection activity of a supermarket was also successfully shared as good news. The audience does not tend to reject advertisements when they are embedded in enjoyable comics. The audience was very engaged and reminded each other "Discounts are only on Wednesday, don't get it wrong!” as well as whether if the discount was limited to credit card members.

In the 64 comics posted by Researcher B, 10 contained marketing information and had an average of 61.2 likes, which was not significantly different from the total average of 60.8 likes. Students were not defensive against the information. Since Researcher B was the student body president, it was suitable for her to promote campus activities and good courses.

Of course, there was also more commercial information placed in the comics, such as Fig.5 showing large pizza buy one get one free, which received 70 likes and 18 comments discussing their favorite flavor and immediately making an order.

Compared with courses and events, students were the most unable to resist food, any comic with food in it, whether it may be recommending a café (Fig. 12), burger shop or snack shop, an expert would immediately appear and begin a heated discussion. Such comics with placement advertising received an average of 6 comments, higher than the overall average of 3.5 comments.

Students were also concerned about computer brands, what brands of flash drives are better, and constructive topics beneficial to their performance at school. Any product can create business opportunities if it can start a discussion.

Of the 90 comics made by Researcher C, 18 had product information embedded in them and received an average of 45 likes, which was not significantly different from the overall average of 44.1 likes. Researcher $C$ is a computer engineer who is interested in photography, so his friends completely believed in the camera brand he recommended (56 likes and 3 comments).

He also used a comic to show him and his wife reliving how they met in a restaurant on their 
anniversary (similar to Fig. 9 but with different actors). The comic resonated with the audience (37 comments), who made it seem as if they all helped in their relationship. The comic also helped promote the restaurant.

Since the newlyweds had a baby on the way, Researcher $\mathrm{C}$ posted the baby products he thought were the best, umbilical cord blood storage, and baby pen preservation. All of the comics drew attention and started discussions; the comics with marketing information received an average of 6 comments, higher than the overall average of 4.2 comments.

These results indicate that the audience does not tend to reject advertisements when they are embedded in enjoyable comic. This model can thus be used for other commercial applications. Story marketing is the latest trend, and recommendations from friends are more persuasive. When such comics contain stories with product information and are acted by friends, others find it interesting and are more willing to accept the product.

This experiment has already drawn the attention of businesses. We found that the comic on the gaming expo in the world trade center (Fig. 12) was shared by the general manager of EC Life to promote the event; the comic shown in Fig. 13 to recommend a coffee shop was shared by the owner on the shop's fan page.

This is a good start. We do not expect these comics to replace commercial advertisements, but they do not cost a single dollar. Owners only need to use their hands and target the right audience to advertise their business. It is an advertisement method that is worth a try, especially on a low budget.

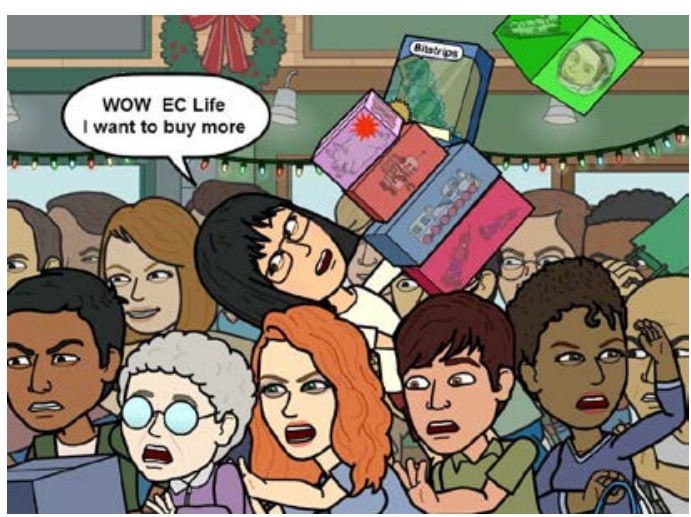

Fig. 12. Successful sharing by businesses

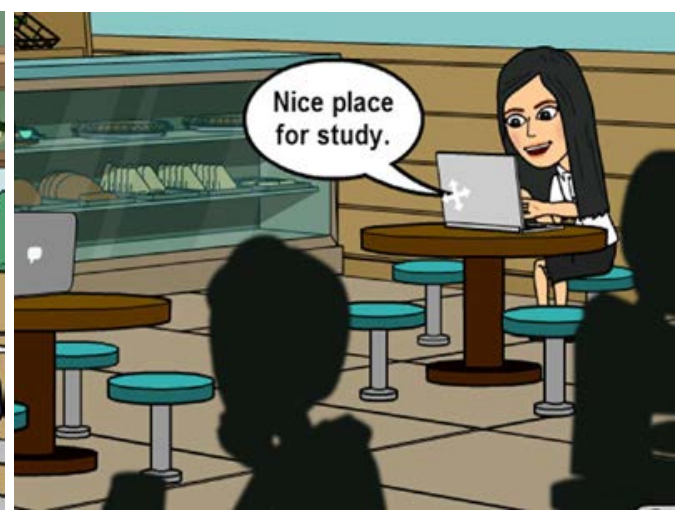

Fig. 13. Shop owner post on the fan page

When the positive dialog combining a suitable product with an interesting element, such as gift giving, romantic things, news, or popular topics will cause the comic containing the product to receive greater than average attention even helping to promote . In this way, Facebook and comic application software can be used not only for fun, but also for business.

This study found that media workers liked to discuss movies, TV programs and news, students like to discuss food, and white collar workers were the most interested in travel and health related topics. Things of one kind come together, and the groups of friends on Facebook have already segmented the market for us as they each have their own preferences. Knowing this, we can embed products targeting specific groups when making comics, and can achieve even better effects by inviting the opinion leader of each group to help us. 


\section{Discussion and Conclusion}

This study highlights that everyone these days is in a Wedia network environment, wherein the Wedia's function is not limited to publishing news, but offers space for more creative performances such as DIY comics. This is the first time Wedia was combined with dramaturgy. All of the symbols, such as role, scene, and dialog, are controllable, and creativity with a funny story is the key to communication success with the audience. The dialogue between avatars was the key to whether if a comic was popular.

Embedding some information skillfully in the comic could increase the frequency with which that information is liked, commented on, and shared. In such a context, advertisements are no longer hated; thus, this approach to embedding information could be a first step toward influencing purchase behavior. More research on placement marketing and sales impacts would be useful to confirm this possibility.

Even though the research sample includes 8,008 Facebook users, which is not a very low number, it was a convenient sample accessible to the 3 researchers. The internet has a volatile ecosystem, and the number of users in the sample and users of the APP will be more uncontrollable over a longer research period. Hence, the research period was set at 9 months. To prevent comics from interfering with each other if they are posted too frequently, we usually posted a new comic every 2 days and posted 265 comics in total. The representativeness of this number, quite frankly, is another limitation of this study.

At least, we found that online comics like the ones we created using Bitstrips can indeed be used for promotion, and that the model can thus be used for other commercial applications. Comics we made using this APP have already attracted the attention of businesses, and two proprietors have used our comics for promotion. After all, the comics are not expensive like traditional advertisements and can easily be made by anyone. We found that different Facebook groups are interested in different product information, which is consistent with the marketing concept that segmentation is more effective than targeting the masses. Hence, the experiment can be replicated and applied to any product or group. Now, it is up to Wedia operators to take the initiative.

\section{References}

[1] D. Gillmor, "We the media: Technology empowers a new grassroots journalism," in Proc. of the 15th ACM conference on Hypertext and hypermedia, Santa Cruz, CA, pp. 270-271, August, 2004. Article (CrossRef Link)

[2] P. Bourdieu, Bourdieu and the Journalistic Field, Benson, R. and Neveu, E., eds., Polity Press, Cambridge, MA, pp. 29-47, 2005.

[3] L. P. Spyridou, M. Matsiola, A. Veglis, G. Kalliris and C. Dimoulas, "Journalism in a state of flux: Journalists as agents of technology innovation and emerging news practices," International Communication Gazette, vol. 75, no. 1, pp. 76-98, 2013. Article (CrossRef Link)

[4] M. Le Masurier, "Independent magazines and the rejuvenation of print," International Journal of Cultural Studies, vol. 15, no. 4, pp. 383-398, 2012. Article (CrossRef Link)

[5] M. Burawoy, "The extended case method," Sociological Theory, vol. 16, no. 1, pp. 4-33, 1998. Article (CrossRef Link)

[6] L. Moyo, "Blogging down a dictatorship: Human rights, citizen journalists and the right to communicate in Zimbabwe,” Journalism, vol. 12, no. 6, pp. 745-760, 2011. Article (CrossRef Link).

[7] E. R. Goffman, The Presentation of Self in Everyday Life, Double-Day, New York, 1959. 
[8] P. K. Manning, "Dramaturgy, politics and the axial media event,” Sociological Quarterly, vol. 37, no. 2, pp. 261-278, 1996. Article (CrossRef Link)

[9] R. Kossakowski, "Between dramaturgy and totality: A call center in the perspective of Erving Goffman's sociology,” Studia Socjologiczne, vol. 1, no. 188, pp. 77-98, 2008.

[10] N. Wilson, "Interaction without walls: Analysing leadership discourse through dramaturgy and participation,” Journal of Sociolinguistics, vol. 17, no. 2, pp. 180-199, 2013. Article (CrossRef Link)

[11] J. T. Howell, Hard Living on Clay Street: Portraits of Blue Collar Families, Waveland Press, Inc., Prospect Heights, IL, pp. 392-403, 1972.

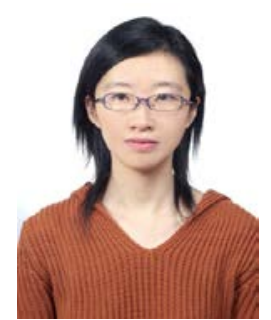

Jia-Wen Hu was born in Taipei, Taiwan, in 1971. She received a Bachelor's degree in Mass Communication from the Tamkang University of Taiwan in 1993 and a Master's degree in business administration from National Taiwan University of Science and Technology (NTUST), Taiwan in 2012. From 1995 to 2012, she was a well-known TV director in Taiwan. Since 2013, she has taught Communication and Media at NTUST, And then get teaching innovation award. Miss Hu is currently a Ph.D. student at NTUST, Her research interests include dramaturgy, multimedia, MOOCs, and social networking sites.

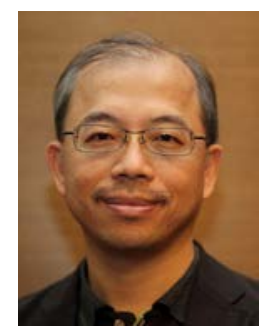

Seng-Su Tsang is Associate Professor of Business Strategy in Department of Business Administration at National Taiwan University of Science and Technology since 2008. His current research interests include innovations and strategies in services. Current applied research projects emphasize innovations via clustering, a project sponsored by government funding, Taiwan. He is engaged with a research team in developing business models for small and medium sized firms in achieving business excellence through service innovation among networked firms. He received BS in chemical engineering from Tsinghua University, Taiwan, MBA from Sun Yat-sen University, Taiwan, and Ph.D. in public policy and management from Carnegie Mellon University, USA. His dissertation was written on cooperative games. He is a member of Phi Tau Phi, branch of Sun Yat-sen University in 1989. He published peer reviewed papers in areas including retailing, technology management and services. 